\title{
Meticulous closure of collateral vessels in the perihilar mediastinal pleura to control intraoperative bleeding during lung transplantation for pulmonary hypertension
}

\author{
Haruchika Yamamoto, Seiichiro Sugimoto^, Kentaro Imanishi, Kohei Hashimoto, Kentaroh Miyoshi, \\ Shinji Otani, Masaomi Yamane, Shinichi Toyooka
}

Department of General Thoracic Surgery and Organ Transplant Center, Okayama University Hospital, Okayama, Japan

Contributions: (I) Conception and design: H Yamamoto, S Sugimoto; (II) Administrative support: None; (III) Provision of study materials or patients: H Yamamoto, S Sugimoto; (IV) Collection and assembly of data: H Yamamoto, S Sugimoto, K Imanishi, K Hashimoto, K Miyoshi, S Otani, M Yamane; (V) Data analysis and interpretation: H Yamamoto, S Sugimoto, S Toyooka; (VI) Manuscript writing: All authors; (VII) Final approval of manuscript: All authors.

Correspondence to: Seiichiro Sugimoto, MD, PhD. Department of General Thoracic Surgery and Organ Transplant Center, Okayama University Hospital, 2-5-1 Shikata-cho, Kita-ku, Okayama-city, Okayama 700-8558, Japan. Email: sugimo-s@cc.okayama-u.ac.jp.

\begin{abstract}
Background: Massive blood transfusion compensating hemorrhage during lung transplantation (LT) results in primary graft dysfunction (PGD) and worse outcomes after LT. Collateral vessels in the perihilar mediastinal pleura could be the source of hemorrhage during LT in patients with pulmonary hypertension (PH). The purpose of this study was to examine the effect of closure with hemoclips of the vessels in the perihilar mediastinal pleura on the risk of intraoperative hemorrhage and outcomes after LT in patients with PH.

Methods: We retrospectively reviewed 80 patients who underwent LT, including 13 patients with primary $\mathrm{PH}, 29$ patients with secondary $\mathrm{PH}$, and 38 patients with non-PH.

Results: The median number of hemoclips was significantly higher in the primary $\mathrm{PH}$ group than in the non-PH group $(\mathrm{P}=0.0045)$ or secondary $\mathrm{PH}$ group $(\mathrm{P}=0.0060)$. The intraoperative blood loss, transfusion volume, maximum PGD grade, and the 30-day and 90-day mortality rates in the primary $\mathrm{PH}$ group were equivalent to those in the other two groups.

Conclusions: Meticulous closure of collateral vessels in the perihilar mediastinal pleura during LT in patients with primary $\mathrm{PH}$ allowed intraoperative hemorrhage to be controlled and might be associated with acceptable mortality rate in these patients similar to that of LT in patients with other diseases.
\end{abstract}

Keywords: Lung transplantation (LT); pulmonary hypertension (PH); collateral vessel; bleeding; mortality

Submitted Jul 07, 2021. Accepted for publication Sep 16, 2021.

doi: $10.21037 /$ jtd-21-1119

View this article at: https://dx.doi.org/10.21037/jtd-21-1119

\section{Introduction}

Lung transplantation (LT) is indispensable for patients with progressive pulmonary hypertension $(\mathrm{PH})$ despite optimized medical therapy $(1,2)$. However, patients with primary $\mathrm{PH}$ are at a higher risk of developing primary graft dysfunction (PGD), as well as show higher 30-day and 90-day mortality rates, after LT than patients with other pulmonary diseases undergoing LT (3-5). Moreover, patients with secondary $\mathrm{PH}$, who have mean pulmonary arterial pressure (PAP) values of $\geq 25 \mathrm{mmHg}$ secondary to underlying lung diseases, are also at an elevated risk of PGD and decreased long-term survival (6,7). Most patients with

$\wedge$ ORCID: 0000-0001-6649-4777. 
$\mathrm{PH}$ require cardiopulmonary support, such as with venoarterial extracorporeal membrane oxygenation (ECMO) and cardiopulmonary bypass (CPB), during LT, as they cannot tolerate hemodynamically during single-lung perfusion after hilar clamping (8). Consequently, the use of anticoagulation for cardiopulmonary support could increase the risk of massive hemorrhage and the need for massive fluid infusion and blood/blood product transfusion during LT, which increases the risk of development of PGD after LT (9).

In the patients with primary $\mathrm{PH}$, the elevated pulmonary pressure has been shown to cause neovascularization of the vasa vasorum and remodeling of the collateral vessels in the perihilar mediastinal pleura (10-15). Unintentional injury of the collateral vessels in the perihilar mediastinal pleura, consequent to their becoming less visible due to the decreased blood flow during cardiopulmonary support, could result in uncontrollable bleeding during LT in patients with $\mathrm{PH}$. In fact, postoperative blood loss within 24 hours of LT has been reported to be significantly higher in patients with $\mathrm{PH}$ than in those with other diseases (16). To decrease the blood loss during LT in patients with PH, preventive closure of collateral vessels in the perihilar mediastinal pleura might be useful, especially in patients undergoing LT under cardiopulmonary support. However, the effect of preventive closure of collateral vessels in the perihilar mediastinal pleura during LT in patients with PH remains to be clearly determined. We hypothesized that a higher number of hemoclips are required to attain meticulous hemostasis in the patients with primary $\mathrm{PH}$ as compared to those with secondary $\mathrm{PH}$ or non-PH. The purpose of this study was to examine the effect of preventive closure of collateral vessels in the perihilar mediastinal pleura using hemoclips on the risk of intraoperative bleeding and outcomes of LT in patients with and without primary or secondary $\mathrm{PH}$. We present the following article in accordance with the STROBE reporting checklist (available at https://dx.doi.org/10.21037/jtd-21-1119).

\section{Methods}

\section{Patients}

This was a single-center retrospective cohort study conducted at Okayama University Hospital between February 2008 and August 2015. A total of 85 patients who had undergone LT were included in this study; however, 5 patients who underwent repeat transplantation during the study period were excluded from this study. The remaining
80 recipients, including 27 recipients of living-donor lobar LT (LDLLT) and 53 recipients of cadaveric LT (CLT), were divided into the following three groups: patients with primary $\mathrm{PH}$ (primary $\mathrm{PH}$ group, $\mathrm{N}=13$ ), patients with secondary $\mathrm{PH}$ (secondary $\mathrm{PH}$ group, $\mathrm{N}=29$ ), and patients without $\mathrm{PH}$ (non-PH group, $\mathrm{N}=38$ ) (Figure 1). The primary PH group included patients with pulmonary arterial hypertension ( $\mathrm{PAH}, \mathrm{N}=8$ ), pulmonary veno-occlusive disease (PVOD, N=3), and chronic thromboembolic pulmonary hypertension (CTEPH, N=2). Patients with mean PAP values of $\geq 25 \mathrm{~mm} \mathrm{Hg}$ resulting from underlying lung diseases were defined as having secondary PH. This protocol of this retrospective study (No. 2008-011) was approved by the Institutional Review Board of Okayama University Hospital. Informed consent was obtained in the form of opt-out on the website. The study was conducted in accordance with the Declaration of Helsinki (as revised in 2013).

The preoperative and intraoperative characteristics and postoperative outcomes were compared among the three groups. The lung allocation score (LAS) was calculated to assess the preoperative disease severity in the recipients (17), using the LAS calculator published on the OPTN website (https://optn.transplant.hrsa.gov/resources/allocationcalculators/lascalculator/). The maximum total number of HLA mismatches could equal 12 in cases of LDLLT, because LDLLT involves two different donors for each recipient (18). The prognostic nutrition index (PNI) was calculated using the following equation: $\mathrm{PNI}=[10 \times$ serum albumin $(\mathrm{g} / \mathrm{dL})]+[0.005$ $\times$ total lymphocyte count $\left.\left(/ \mathrm{mm}^{3}\right)\right](19)$. The preoperative mean PAP was assessed by right-heart catheterization immediately after the induction of general anesthesia for LT. CPB was exclusively used for cardiopulmonary support during LT. The graft ischemic time was defined as the ischemic time up to the second LT. The total transfusion volume was calculated from the amounts of packed red blood cells (RBC), fresh-frozen plasma (FFP), and platelet concentrates (PC) administered during the operation. The PGD grades in the patients were assigned according to the definition of PGD proposed by the International Society for Heart and Lung Transplantation (ISHLT) (20). Chronic lung allograft dysfunction (CLAD) was diagnosed by a decline of the forced expiratory volume in $1 \mathrm{~s}$ (FEV1) to $<80 \%$ of the baseline; The FEV1 was calculated as the average of the two best FEV1 values obtained at least 3 weeks apart, according to the classification system proposed by the ISHLT (21). In addition, subgroup analysis for total amount of blood loss was performed according to 


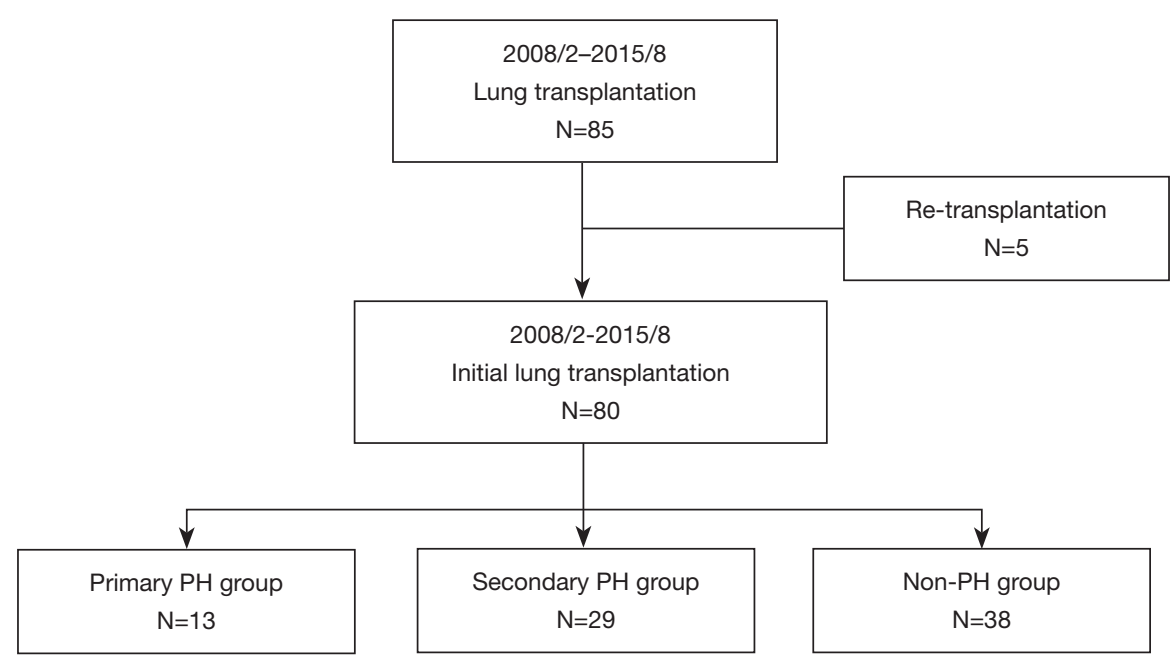

Figure 1 Flow-diagram of this study cohort. Lung Transplantation was performed in 85 patients during the study period; of these, five patients who underwent repeat transplantation were excluded from this study. The remaining 80 patients were divided into 3 groups according to the diagnosis of primary or secondary $\mathrm{PH}$, as follows: primary $\mathrm{PH}$ group $(\mathrm{N}=13)$, secondary $\mathrm{PH}$ group (N=29), and non- $\mathrm{PH}$ group ( $\mathrm{N}=38)$. $\mathrm{PH}$, pulmonary hypertension.

primary PH subcategories: PAH, PVOD, and CTEPH. Also, subgroup analysis for total number of hemoclips and total amount of blood loss was performed in the patients of secondary $\mathrm{PH}$ with and without bronchiectasis.

\section{The technique of closure of collateral vessels in the peribilar mediastinal pleura with hemoclips and the method of counting of hemoclips}

Hilar dissection was routinely performed before the establishment of CPB prior to the LT. During the hilar dissection, collateral vessels in the perihilar mediastinal pleura containing the circumferential connective and adipose tissue around the hilar structures, including the pulmonary artery, the pulmonary vein and the main bronchus as well as the bronchial arteries, lymph nodes, pleural adhesions and the pulmonary ligament, were meticulously closed with hemoclips (Weck ${ }^{\circledR}$ horizon $^{\mathrm{TM}}$ metal ligation system, Teleflex Medical, North Carolina, USA) (Figure 2). After closure of the central collateral vessels using hemoclips, the peripheral collateral vessels were divided by electrocautery.

The total number of hemoclips were retrospectively counted on frontal-view chest X-ray images obtained after the LT by two surgeons (H.Y. and K.I.), and the average of two values determined by the examiners was used for the analysis in this study (Figure 3A,3B). The contrast of X-ray images was adjusted to enhance the hemoclip metal during the counting.

\section{Statistical analysis}

All statistical analyses were performed using EZR version 1.40 (Saitama Medical Center, Jichi Medical University, Saitama, Japan), which is a graphical user interface for $\mathrm{R}$ version 3.5.2 (The R Foundation for Statistical Computing, Vienna, Austria). Specifically, the software is a modified version of $\mathrm{R}$ commander, designed to add statistical functions frequently used in biostatistics (22). GraphPad Prism 7.04 software program (San Diego, CA, USA) was used for graph editing. Differences in patient characteristics between any two groups were tested by the Pearson's chisquare test for categorical variables and by the KruskalWallis test for continuous variables. The Bonferroni correction was employed for multiple comparisons (primary $\mathrm{PH}$ vs. secondary $\mathrm{PH}$, primary $\mathrm{PH}$ vs. non- $\mathrm{PH}$, and secondary $\mathrm{PH} v s$. non-PH). The overall survival and CLAD-free survival were analyzed using the Kaplan-Meier method, and differences among the groups were compared by the log-rank test. Subgroup analysis for total amount of blood loss in primary $\mathrm{PH}$ subcategories was tested by the Kruskal-Wallis test and Bonferroni correction was employed for multiple comparisons (PAH vs. PVOD, $\mathrm{PH}$ vs. CTEPH, and PVOD vs. CTEPH). Subgroup analysis 

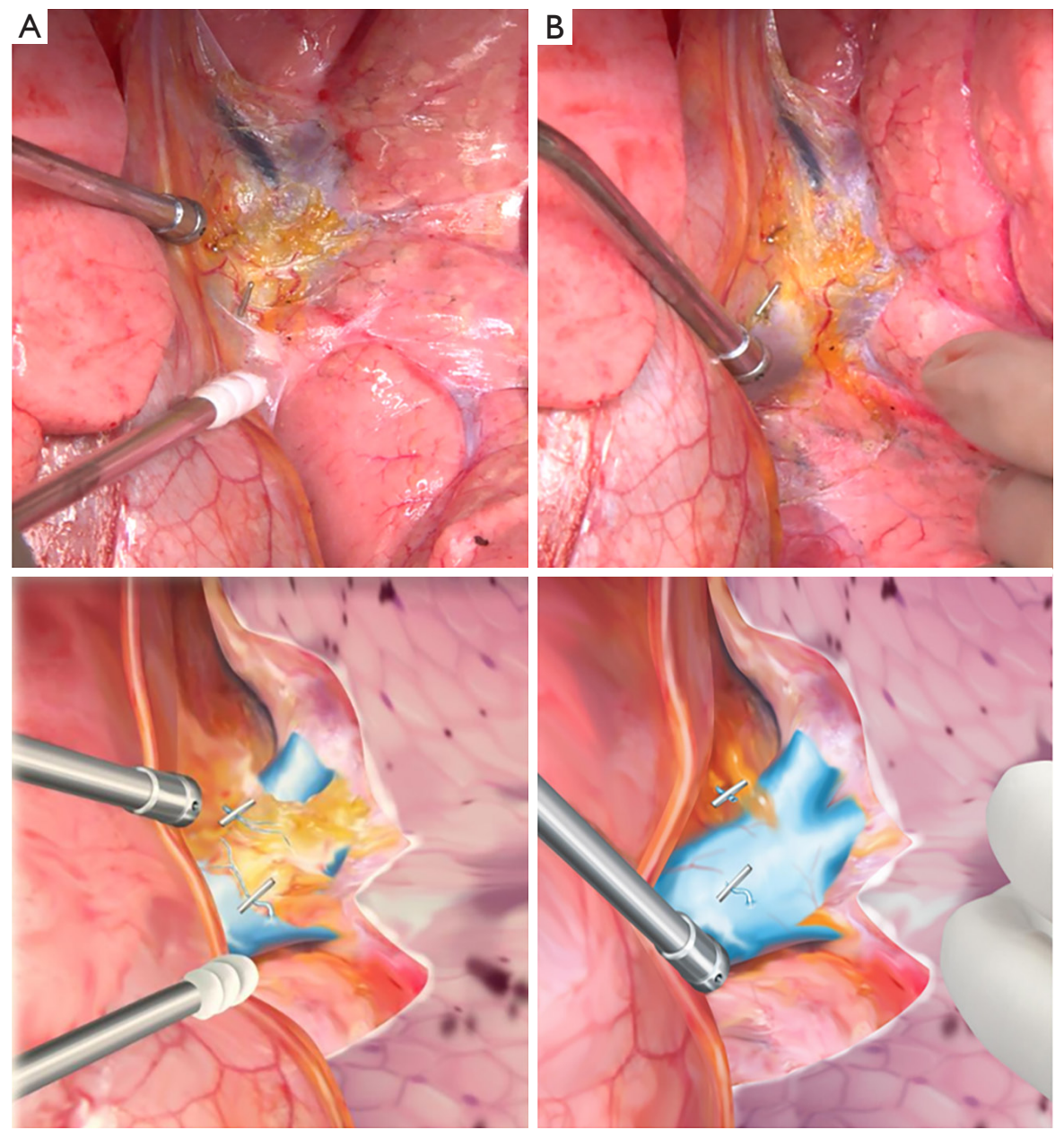

Figure 2 Intraoperative photographs and illustrations of preventive closure of collateral vessels in the perihilar mediastinal pleura using hemoclips. The collateral vessels on the left superior pulmonary vein were closed with hemoclips (A) and divided by electrocautery (B).

for total number of hemoclips and total amount of blood loss in the patients of secondary $\mathrm{PH}$ with and without bronchiectasis was performed by Mann-Whitney $\mathrm{U}$ test. Differences at $\mathrm{P}<0.05$ (two-sided) were considered as being significant. Missing data were not replaced.

\section{Results}

Table 1 shows the preoperative patient characteristics. Interstitial lung disease (58.6\%) was the most frequent cause of secondary $\mathrm{PH}$ in the secondary $\mathrm{PH}$ group. Although $69 \%$ of the patients in the primary $\mathrm{PH}$ group had received preoperative epoprostenol therapy, no significant differences in the preoperative platelet count were noted among the three groups. While the LAS in the primary $\mathrm{PH}$ group was similar to that in the secondary $\mathrm{PH}$ group, that in the secondary $\mathrm{PH}$ group was significantly higher than the value in the non- $\mathrm{PH}$ group $(\mathrm{P}=0.032)$. Unsurprisingly, the mean PAP values in the primary $\mathrm{PH}$ group $(\mathrm{P}=0.0074)$ and secondary $\mathrm{PH}$ group $(\mathrm{P}=0.00019)$ were significantly higher than the mean PAP in the non-PH group.

As shown in Table 2, single LDLLT was performed in two patients of the primary $\mathrm{PH}$ group, while in the secondary $\mathrm{PH}$ group, single CLT was performed in three patients and single LDLLT in one patient. The operative time $(\mathrm{P}=0.0070)$, total ischemic time $(\mathrm{P}=0.041)$ and duration of $\mathrm{CPB}(\mathrm{P}=0.013)$ in the secondary $\mathrm{PH}$ group were significantly longer than those in the non$\mathrm{PH}$ group. The rates of intraoperative CPB use did not differ among the three groups. Of note, the total number of hemoclips in the primary $\mathrm{PH}$ group was significantly higher than that in the secondary $\mathrm{PH}$ group $(\mathrm{P}=0.0060)$ 

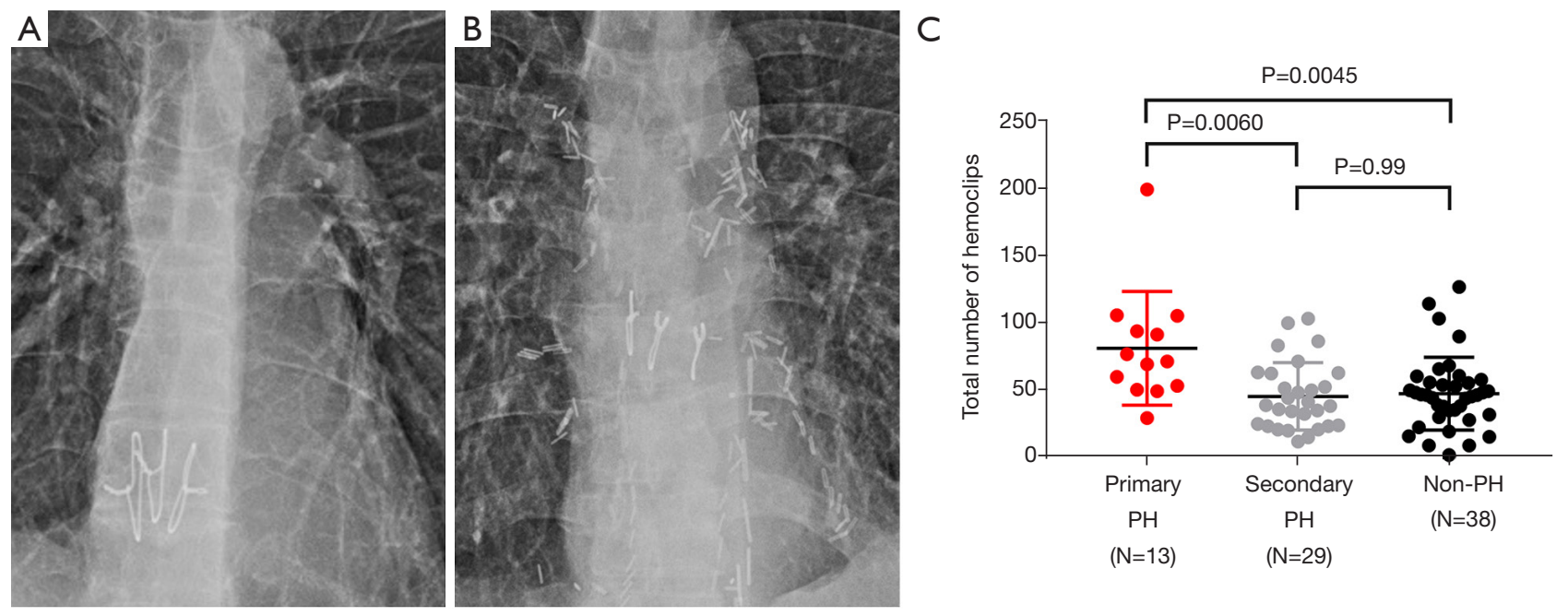

Figure 3 Comparison of the total number of hemoclips on the postoperative frontal-view chest X-ray images. Representative postoperative chest X-rays from the non-PH group (A) and primary $\mathrm{PH}$ group (B). (C) The total number of hemoclips needed was significantly higher in the primary $\mathrm{PH}$ group (median 71.5; range, 29.5-199.5) than in the secondary $\mathrm{PH}$ group (median 39, range 12-103.5, $\mathrm{P}=0.0060$ ) and the non-PH group (median 46.5; range, 2-127, $\mathrm{P}=0.0045$ ). Interestingly, there was no significant difference in the number of clips needed between the secondary $\mathrm{PH}$ group and the non- $\mathrm{PH}$ group $(\mathrm{P}=0.99)$. $\mathrm{PH}$, pulmonary hypertension.

or the non-PH group $(\mathrm{P}=0.0045)$ (Figure $3 C)$. There was no significant difference in the amount of intraoperative blood loss in the subclassification of primary $\mathrm{PH}(\mathrm{P}=0.19$; $\mathrm{PAH}$ vs. $\mathrm{PVOD}, \mathrm{P}=0.99$; $\mathrm{PAH}$ vs. CTEPH, $\mathrm{P}=0.53$; $\mathrm{PVOD}$ vs. CTEPH, $\mathrm{P}=0.99)$. Although the patients of secondary $\mathrm{PH}$ with bronchiectasis had significantly higher amount of intraoperative blood loss $(\mathrm{P}=0.038)$ than those without bronchiectasis, the number of hemoclips did not differ $(\mathrm{P}=0.23)$. By contrast, there was no significant difference in the volume of blood loss or total volume of transfusion of RBC, FFP, and PC during the LT among the three groups.

The postoperative outcomes are shown in Table 3. In a three-group comparison, the postoperative ECMO support rate was significantly higher in the primary $\mathrm{PH}$ group $(\mathrm{P}=0.019)$. Early outcomes after the LT in terms of the maximum grade of PGD, and incidences of acute rejection and antibody-mediated rejection were not statistically significantly different among the three groups. Also, 30 - and 90-day mortality were similar among the three groups. The overall survival in the primary $\mathrm{PH}$ group was comparable to that in the secondary $\mathrm{PH}$ group $(\mathrm{P}=0.99)$ and the non- $\mathrm{PH}$ group $(\mathrm{P}=0.37)$, whereas the overall survival in the secondary $\mathrm{PH}$ group was significantly worse than that in the non- $\mathrm{PH}$ group (Figure $4 A, \mathrm{P}=0.041$ ). The CLAD-free survival rates did not differ among the three groups (Figure 4B).

\section{Discussion}

In this study, we found that the total number of hemoclips needed for preventive closure of the collateral vessels in the perihilar mediastinal pleura during LT was significantly higher in the primary $\mathrm{PH}$ group than in the other two groups. By contrast, we found no significant differences in other intraoperative variables, postoperative early outcomes, including volume of blood loss, the total volume of transfusion of RBC, FFP and PC, or 30- and 90-day mortality rates among the three groups, except that the secondary $\mathrm{PH}$ group showed significantly worse survival as compared to the non-PH group in the chronic phase. Our results suggest that patients with primary $\mathrm{PH}$ could have more abundant collateral vessels in the perihilar mediastinal pleura as compared to patients with other diseases undergoing LT; therefore, meticulous closure of the collateral vessels in the patients with primary $\mathrm{PH}$ could contribute to control of intraoperative bleeding despite the use of CPB/anticoagulation, and similar outcomes to those in patients with other diseases undergoing LT could be obtained. To the best of our knowledge, this is the first report to examine the effect of preventive closure 


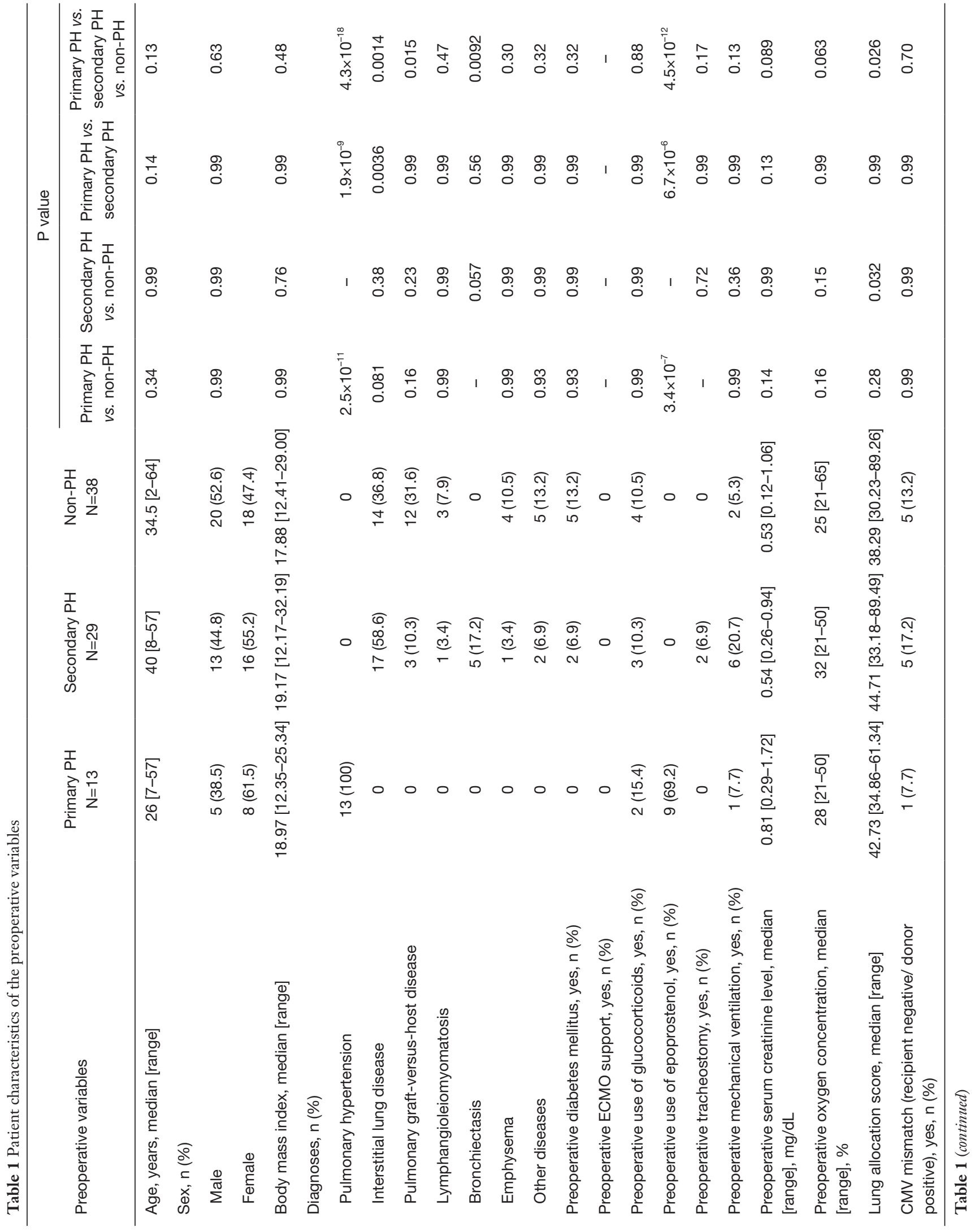




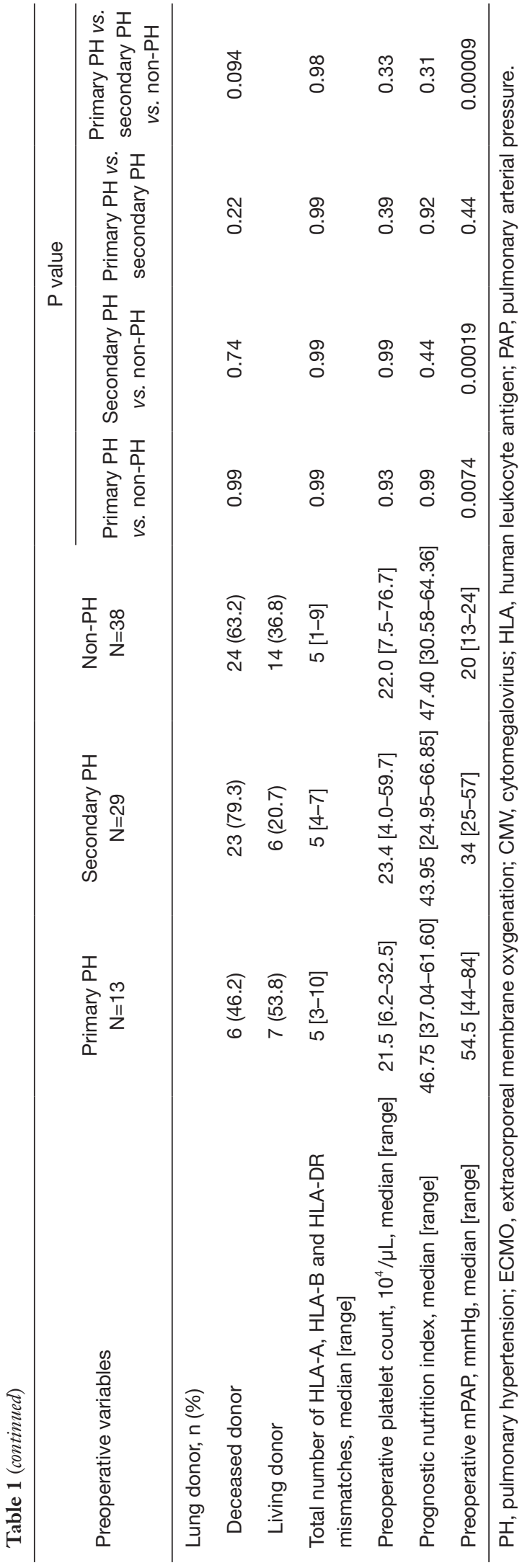

of collateral vessels in the perihilar mediastinal pleura on the risk of intraoperative bleeding and outcomes of LT in patients with $\mathrm{PH}$.

Obviously, patients with primary $\mathrm{PH}$ had higher preoperative mean PAP values and received preoperative epoprostenol therapy more frequently, necessitating use of postoperative ECMO at a higher frequency due to decreased cardiac function as compared to the non- $\mathrm{PH}$ group (23). Although preoperative epoprostenol therapy causes vasodilation and inhibition of platelet aggregation (24-27), resulting in thrombocytopenia and easy bleeding, the preoperative platelet counts did not differ significantly among the three groups in this study. The high rate of interstitial lung disease as the cause of secondary $\mathrm{PH}$ could be attributed to the long waiting time for CLT, due to the severe shortage of donors in Japan $(24,25)$. LT for secondary $\mathrm{PH}$ has been shown to yield equivalent survival to that for non-PH conditions (6); however, we speculated that the overall survival in the secondary $\mathrm{PH}$ group was worse than that in the non-PH group in this study, because the secondary $\mathrm{PH}$ group had a higher LAS than the non-PH group.

The total number of hemoclips needed was significantly higher in the primary $\mathrm{PH}$ group than in the other two groups, suggesting that the patients with primary $\mathrm{PH}$ had a higher number of collateral vessels in the perihilar mediastinal pleura as compared to the patients with secondary $\mathrm{PH}$ and patients without $\mathrm{PH}$ undergoing LT. Our results lend support to the notion that in patients with primary $\mathrm{PH}$, hypoxia and endothelin-1 serve as potent stimuli for the growth of new vessels, resulting in neovascularization of the vasa vasorum and remodeling of collateral vessels (10-15). Although we mainly use monopolar electrocautery during LT, division of the collateral vessels by electrocautery alone is associated with the risk of after-bleeding, especially under the condition of anticoagulation used for CPB or veno-arterial ECMO, which is generally required for LT in patients with primary PH (26-29). Recently, veno-arterial ECMO has been increasingly utilized as an alternative cardiopulmonary support with benefits for post-transplant outcomes $(27,28)$. ECMO is theoretically less invasive than conventional $\mathrm{CPB}$ and reduces the inflammatory response as well as the need for full heparinization. CPB use was associated with a significantly higher incidence of PGD; however, $\mathrm{CPB}$ provides safer, easier and more versatile surgical fields than ECMO (29). Moreover, meticulous management of graft reperfusion flow and low oxygen concentration ventilation with $\mathrm{CPB}$ contribute to comparable short- and 
Table 2 Patient characteristics of the intraoperative variables

\begin{tabular}{|c|c|c|c|c|c|c|c|}
\hline $\begin{array}{l}\text { Intraoperative } \\
\text { variables }\end{array}$ & $\begin{array}{l}\text { Primary PH } \\
\qquad N=13\end{array}$ & $\begin{array}{l}\text { Secondary PH } \\
\quad \mathrm{N}=29\end{array}$ & $\begin{array}{l}\text { Non-PH } \\
N=38\end{array}$ & \multicolumn{4}{|c|}{$P$ value } \\
\hline \multicolumn{8}{|c|}{ Lung transplant procedure, $\mathrm{n}(\%)$} \\
\hline Single & $2(15.4)$ & $4(13.8)$ & $12(31.6)$ & 0.99 & 0.48 & 0.99 & 0.18 \\
\hline $\begin{array}{l}\text { Operative time ( } \mathrm{min}) \text {, } \\
\text { median [range] }\end{array}$ & 554 [422-690] & 571 [257-845] & 471 [238-785] & 0.097 & 0.007 & 0.99 & 0.0043 \\
\hline $\begin{array}{l}\text { Ischemic time (min), } \\
\text { median [range] }\end{array}$ & 163 [84-683] & 532 [82-787] & 337 [74-628] & 0.99 & 0.041 & 0.37 & 0.041 \\
\hline $\begin{array}{l}\text { Duration of } \\
\text { cardiopulmonary } \\
\text { bypass (min), median } \\
\text { [range] }\end{array}$ & 264 [120-433] & 258 [151-565] & 231 [115-263] & 0.22 & 0.013 & 0.99 & 0.013 \\
\hline $\begin{array}{l}\text { Total amount of blood } \\
\text { loss, ml, median } \\
\text { [range] }\end{array}$ & $1320[370-7,620]$ & $1770[200-15,860]$ & $765[30-8,800]$ & 0.59 & 0.12 & 0.99 & 0.098 \\
\hline $\begin{array}{l}\text { Total amount of RBC, } \\
\text { ml, median [range] }\end{array}$ & $560[51.8-5,040]$ & $560[0-6,720]$ & $560[0-2,240]$ & 0.85 & 0.3 & 0.99 & 0.22 \\
\hline $\begin{array}{l}\text { Total amount of FFP, } \\
\text { ml, median [range] }\end{array}$ & $1,200[240-2,880]$ & $720[0-3,120]$ & $720[0-2,400]$ & 0.23 & 0.99 & 0.99 & 0.2 \\
\hline
\end{tabular}

$\mathrm{PH}$, pulmonary hypertension; RBC, red blood cells; FFP, fresh-frozen plasma; PC, platelet concentrates.

long-term outcomes of LT using extended criteria donor lungs as compared to ECMO (29). For these reasons, we had used CPB as the first choice for LT at our institution during the study period. In addition to anticoagulant therapy, electrocautery dissection of collateral vessels while using cardiopulmonary support, when the blood pressure is low, might cause rebleeding after normalization of the blood pressure following weaning from the cardiopulmonary support. To secure hemostasis during LT under cardiopulmonary support, we adopted preventive closure of the collateral vessels with hemoclips during hilar dissection for LT. In addition to the use of electrocautery, routine use of hemoclips allowed mechanical closure of the mediastinal pleura, securing hemostasis during hilar dissection. Furthermore, single lung ventilation using double-lumen endotracheal tube can provide working space in the surgical field and contribute to hemostasis especially of the dorsal portion of the hilum, which could be difficult after reperfusion and reventilation of the grafts. At present, a vessel sealing system (30), which has excellent hemostatic properties, that has been developed to be elaborate enough for hilar dissection is available, which might offer the potential to secure hemostasis as an alternative method to the use of hemoclips.

While patients with primary $\mathrm{PH}$ have been shown to have the lowest one-year survival rates after LT, their longterm survival is similar to the survival of patients with cystic fibrosis or alpha-1 antitrypsin deficiency $(2,31,32)$. Improvement of the surgical mortality is the key to improving the one-year survival after LT in patients with 
Table 3 Patient characteristics of the postoperative variables

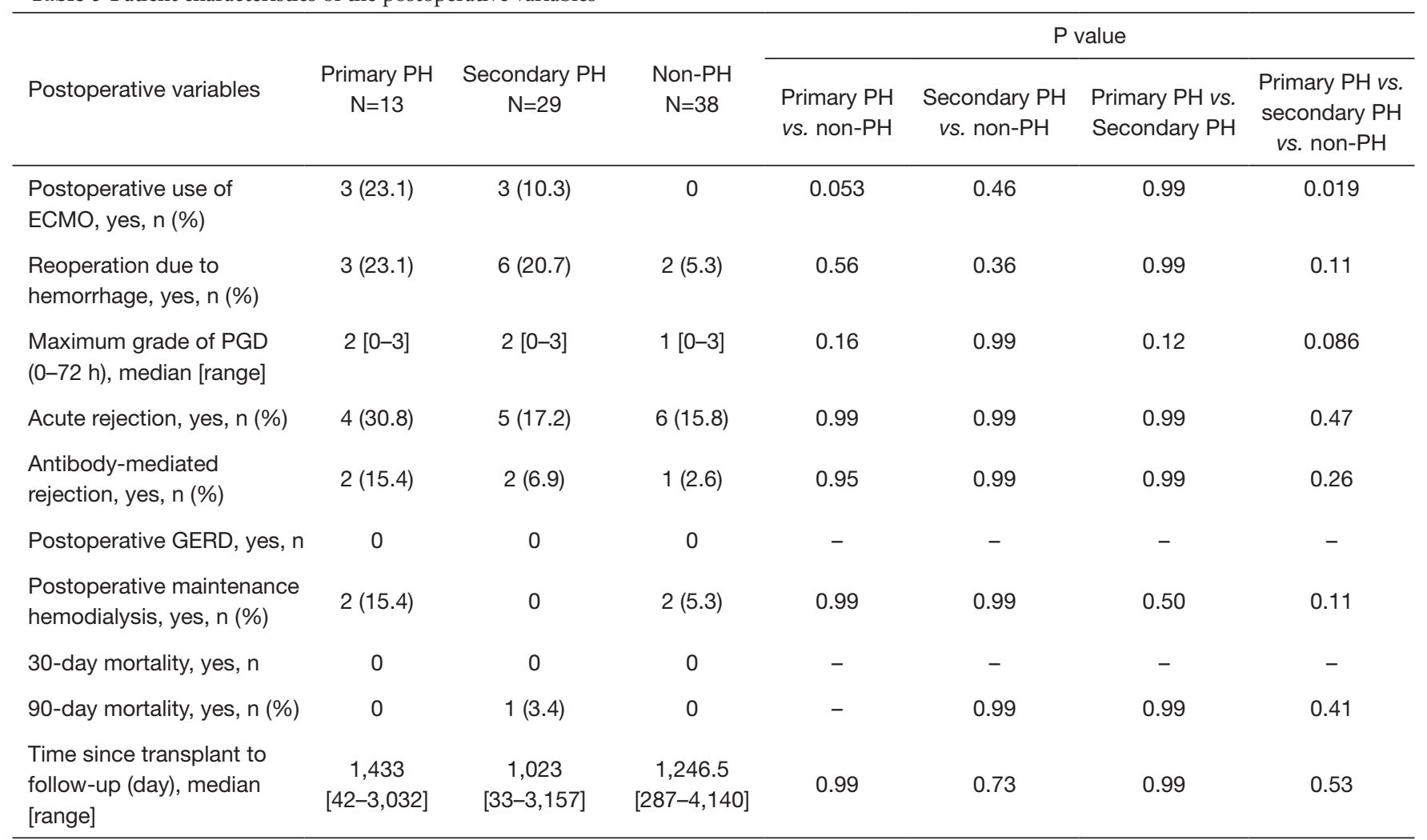

$\mathrm{PH}$, pulmonary hypertension; ECMO, extracorporeal membrane oxygenation; PGD, primary graft dysfunction; GERD, gastro esophageal reflux disease.

A

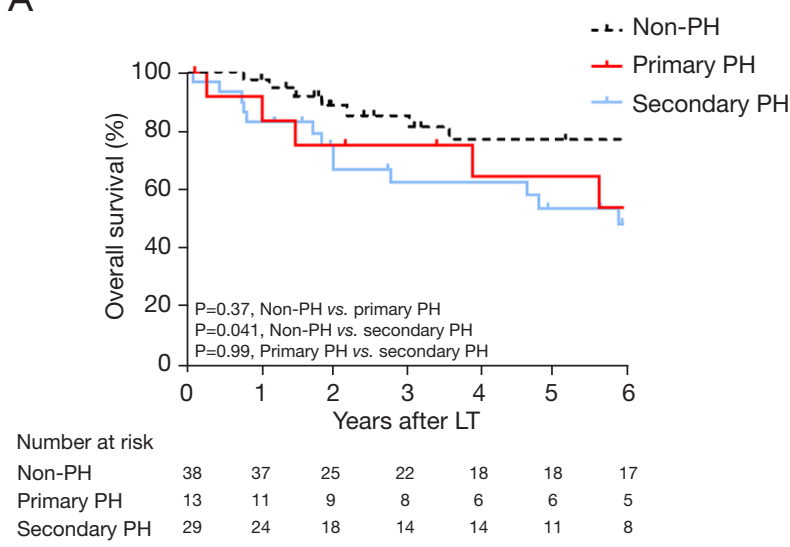

B

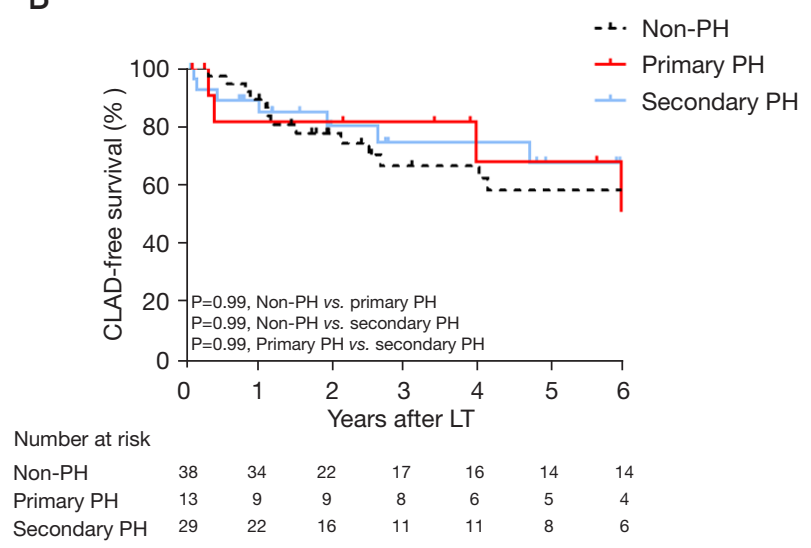

Figure 4 Overall survival and CLAD-free survival rates after lung transplantation. The overall survival rate in the primary PH group was comparable to the overall survival rates in the secondary $\mathrm{PH}$ group $(\mathrm{P}=0.99)$ and the non- $\mathrm{PH}$ group $(\mathrm{P}=0.37)$, whereas the survival rate in the secondary $\mathrm{PH}$ group was significantly worse than that in the non-PH group ( $\mathrm{P}=0.041)$ (A). There were no significant differences in the CLAD-free survival rates among the three groups (B). CLAD, chronic lung allograft dysfunction; PH, pulmonary hypertension. 
primary $\mathrm{PH}$. In this study, the maximum grade of PGD, the 30-day mortality, the 90-day mortality and the overall survival in the primary $\mathrm{PH}$ group were similar to the corresponding values in the non-PH group. Therefore, the control of intraoperative bleeding and blood transfusion in patients with primary $\mathrm{PH}$ could contribute to similar outcomes of LT being obtained in patients with $\mathrm{PH}$ as compared to those in patients without $\mathrm{PH}$.

Several limitations associated with the present study warrant mention. First, this was a retrospective study conducted at a single transplant center, and other than preventive closure of collateral vessels with hemoclips, LT technique might have improved over the years during the study period. Although the single transplant team performed the limited number of LT in the same manner at our institution, the detailed technique could differ among the patients. Second, because the number of patients was small, especially in the primary $\mathrm{PH}$ group, there is a possible risk of Type II statistical error. The follow-up period was intermediate, and longer follow-up periods will be required for the further validation of the effect of preventive hemoclip closure. Third, the amount of intraoperative blood loss might fluctuate according to cardiotomy suction and RBC salvage during CPB. Fourth, the number of hemoclips was retrospectively counted by two surgeons in frontal-view chest X-rays after the LT, and three-dimensional computed tomography might be more precise for counting. Fifth, this study compared the outcomes of preventive hemoclip closure between patients with and without $\mathrm{PH}$ undergoing LT, but not the outcomes in $\mathrm{PH}$ patients undergoing LT with and without preventive hemoclip use, due to ethical reasons.

In conclusion, our study suggests that meticulous closure of collateral vessels in the perihilar mediastinal pleura during LT in patients with primary $\mathrm{PH}$ might control intraoperative bleeding and be associated with acceptable surgical mortality similar to patients undergoing LT for other pulmonary diseases.

\section{Acknowledgments}

Funding: This work was supported by a Grant-in-Aid for Scientific Research (Grant No. 19K09305) from the Japan Society for the Promotion of Science.

\section{Footnote}

Reporting Checklist: The authors have completed the
STROBE reporting checklist. Available at https://dx.doi. org/10.21037/jtd-21-1119

Data Sharing Statement: Available at https://dx.doi. org/10.21037/jtd-21-1119

Peer Review File: Available at https://dx.doi.org/10.21037/ jtd-21-1119

Conflicts of Interest: All authors have completed the ICMJE uniform disclosure form (available at https://dx.doi. org/10.21037/jtd-21-1119). The authors have no conflicts of interest to declare.

Ethical Statement: The authors are accountable for all aspects of the work in ensuring that questions related to the accuracy or integrity of any part of the work are appropriately investigated and resolved. The study was conducted in accordance with the Declaration of Helsinki (as revised in 2013). The protocol of this retrospective study (No. 2008-011) was approved by the Institutional Review Board of Okayama University Hospital. Informed consent was obtained in the form of opt-out on the website. All of the methods used for the study were in compliance with the relevant guidelines and regulations.

Open Access Statement: This is an Open Access article distributed in accordance with the Creative Commons Attribution-NonCommercial-NoDerivs 4.0 International License (CC BY-NC-ND 4.0), which permits the noncommercial replication and distribution of the article with the strict proviso that no changes or edits are made and the original work is properly cited (including links to both the formal publication through the relevant DOI and the license). See: https://creativecommons.org/licenses/by-nc-nd/4.0/.

\section{References}

1. Weill D, Benden C, Corris PA, et al. A consensus document for the selection of lung transplant candidates: 2014--an update from the Pulmonary Transplantation Council of the International Society for Heart and Lung Transplantation. J Heart Lung Transplant 2015;34:1-15.

2. de Perrot M, Granton JT, McRae K, et al. Outcome of patients with pulmonary arterial hypertension referred for lung transplantation: a 14-year single-center experience. J Thorac Cardiovasc Surg 2012;143:910-8.

3. Fang A, Studer S, Kawut SM, et al. Elevated pulmonary 
artery pressure is a risk factor for primary graft dysfunction following lung transplantation for idiopathic pulmonary fibrosis. Chest 2011;139:782-7.

4. Yusen RD, Edwards LB, Kucheryavaya AY, et al. The Registry of the International Society for Heart and Lung Transplantation: Thirty-second Official Adult Lung and Heart-Lung Transplantation Report--2015; Focus Theme: Early Graft Failure. J Heart Lung Transplant 2015;34:1264-77.

5. Sekine Y, Waddell TK, Matte-Martyn A, et al. Risk quantification of early outcome after lung transplantation: donor, recipient, operative, and post-transplant parameters. J Heart Lung Transplant 2004;23:96-104.

6. Fitton TP, Kosowski TR, Barreiro CJ, et al. Impact of secondary pulmonary hypertension on lung transplant outcome. J Heart Lung Transplant 2005;24:1254-9.

7. Nasir BS, Mulvihill MS, Barac YD, et al. Single lung transplantation in patients with severe secondary pulmonary hypertension. J Heart Lung Transplant 2019;38:939-48.

8. Cantu E 3rd, Davis RD 2nd. Surgical Treatment of Pulmonary Arterial Hypertension. Adv Pulm Hypertens 2010;9:31-9.

9. Diamond JM, Lee JC, Kawut SM, et al. Clinical risk factors for primary graft dysfunction after lung transplantation. Am J Respir Crit Care Med 2013;187:527-34.

10. Davie NJ, Crossno JT Jr, Frid MG, et al. Hypoxiainduced pulmonary artery adventitial remodeling and neovascularization: contribution of progenitor cells. Am J Physiol Lung Cell Mol Physiol 2004;286:L668-78.

11. Montani D, Perros F, Gambaryan N, et al. C-kit-positive cells accumulate in remodeled vessels of idiopathic pulmonary arterial hypertension. Am J Respir Crit Care Med 2011;184:116-23.

12. Hayabuchi Y, Homma Y, Kagami S. Optical coherence tomography for observing development of pulmonary arterial vasa vasorum after bidirectional cavopulmonary connection in children. PLoS One 2019;14:e0215146.

13. Nakajima D, Oda $\mathrm{H}$, Mineura $\mathrm{K}$, et al. Livingdonor single-lobe lung transplantation for pulmonary hypertension due to alveolar capillary dysplasia with misalignment of pulmonary veins. Am J Transplant 2020;20:1739-43.

14. Long J, Russo MJ, Muller C, et al. Surgical treatment of pulmonary hypertension: Lung transplantation. Pulm Circ 2011;1:327-33.

15. Davie NJ, Gerasimovskaya EV, Hofmeister SE, et al.
Pulmonary artery adventitial fibroblasts cooperate with vasa vasorum endothelial cells to regulate vasa vasorum neovascularization: a process mediated by hypoxia and endothelin-1. Am J Pathol 2006;168:1793-807.

16. Ueno T, Smith JA, Snell GI, et al. Bilateral sequential single lung transplantation for pulmonary hypertension and Eisenmenger's syndrome. Ann Thorac Surg 2000;69:381-7.

17. Kurosaki T, Miyoshi K, Otani S, et al. Low-risk donor lungs optimize the post-lung transplant outcome for high lung allocation score patients. Surg Today 2018;48:928-35.

18. Sugimoto S, Miyoshi K, Kurosaki T, et al. Favorable survival in lung transplant recipients on preoperative lowdose, as compared to high-dose corticosteroids, after hematopoietic stem cell transplantation. Int J Hematol 2018;107:696-702.

19. Buzby GP, Mullen JL, Matthews DC, et al. Prognostic nutritional index in gastrointestinal surgery. Am J Surg 1980;139:160-7.

20. Diamond JM, Arcasoy S, Kennedy CC, et al. Report of the International Society for Heart and Lung Transplantation Working Group on Primary Lung Graft Dysfunction, part II: Epidemiology, risk factors, and outcomes-A 2016 Consensus Group statement of the International Society for Heart and Lung Transplantation. J Heart Lung Transplant 2017;36:1104-13.

21. Verleden GM, Glanville AR, Lease ED, et al. Chronic lung allograft dysfunction: Definition, diagnostic criteria, and approaches to treatment-A consensus report from the Pulmonary Council of the ISHLT. J Heart Lung Transplant 2019;38:493-503.

22. Kanda Y. Investigation of the freely available easy-touse software 'EZR' for medical statistics. Bone Marrow Transplant 2013;48:452-8.

23. Kanwar MK, Thenappan T, Vachiéry JL. Update in treatment options in pulmonary hypertension. J Heart Lung Transplant 2016;35:695-703.

24. Hoshikawa Y, Okada Y, Ashikari J, et al. Medical consultant system for improving lung transplantation opportunities and outcomes in Japan. Transplant Proc 2015;47:746-50.

25. Sugimoto S, Kurosaki T, Otani S, et al. Feasibility of lung transplantation from donors mechanically ventilated for prolonged periods. Surg Today 2019;49:254-60.

26. Yoshida H, Wu MH, Kouchi Y, et al. Comparison of the effect of monopolar and bipolar cauterization on skeletonized, dissected internal thoracic arteries. J Thorac Cardiovasc Surg 1995;110:504-10. 
27. Biscotti M, Yang J, Sonett J, et al. Comparison of extracorporeal membrane oxygenation versus cardiopulmonary bypass for lung transplantation. J Thorac Cardiovasc Surg 2014;148:2410-5.

28. Ius F, Sommer W, Tudorache I, et al. Five-year experience with intraoperative extracorporeal membrane oxygenation in lung transplantation: Indications and midterm results. J Heart Lung Transplant 2016;35:49-58.

29. Taka H, Miyoshi K, Kurosaki T, et al. Lung transplantation via cardiopulmonary bypass: excellent survival outcomes from extended criteria donors. Gen Thorac Cardiovasc Surg 2019;67:624-32.

30. Sugimoto S, Toyooka S, Iga N, et al. Use of a vessel

Cite this article as: Yamamoto $\mathrm{H}$, Sugimoto $\mathrm{S}$, Imanishi K, Hashimoto K, Miyoshi K, Otani S, Yamane M, Toyooka S. Meticulous closure of collateral vessels in the perihilar mediastinal pleura to control intraoperative bleeding during lung transplantation for pulmonary hypertension. J Thorac Dis 2021;13(10):5658-5669. doi: 10.21037/jtd-21-1119 sealing system versus conventional electrocautery for lung parenchymal resection: a comparison of the clinicopathological outcomes in porcine lungs. Surg Today 2014;44:540-5.

31. Chambers DC, Yusen RD, Cherikh WS, et al. The Registry of the International Society for Heart and Lung Transplantation: Thirty-fourth Adult Lung And HeartLung Transplantation Report-2017; Focus Theme: Allograft ischemic time. J Heart Lung Transplant 2017;36:1047-59.

32. Andersen KH, Schultz HH, Nyholm B, et al. Pulmonary hypertension as a risk factor of mortality after lung transplantation. Clin Transplant 2016;30:357-64. 